\title{
$\mathrm{ZrO}_{2}$ 의 혼합방법 차이가 $\mathrm{ZTA}$ 의 기계적 물성에 미치는 영향
}

\author{
손정호 ${ }^{\dagger}$ \\ 가야대학교 항만물류학부
}

\section{Effect of Difference in Mixing Methods of Zirconia on Mechanical Properties of ZTA}

\author{
Jeongho Sohn ${ }^{\dagger}$
}

School of Port and Logistics, Kaya University, \#208, Samgyero, Simhae, Gyeongsangnamdo 621-748, Korea

\author{
(2013년 10월 21일 접수: 2013년 10월 22일 최종수정 : 2013년 10월 23일 채택)
}

\begin{abstract}
In this study, intermediate-mixed powders were prepared by loading zirconia powders initially in a ball-mill jar and loading alumina powders afterward; the initial-mixed powders were produced by loading zirconia and alumina powders together in the ball-mill jar. The effect of such differences in mixing method on the mechanical properties was investigated. In intermediate-mixed powders, the volume fraction of large particles slightly increased and, simultaneously, zirconia particles formed agglomerates that, due to early ball-mill loading of the zirconia powders only, were more dispersed than were the initialmixed powders. For the intermediate-mixed powders, zirconia agglomerates were destroyed more quickly than were initialmixed powders, so the number of dispersed zirconia particles rose and the inhibitory effect of densification due to the addition of a second phase was more obvious. In the microstructure of intermediate-mixed powders, zirconia grains were homogeneously dispersed and grain growth by coalescence was found to occur with increasing sintering temperature. For the initial-mixed powders, large zirconia grains formed by localized early-densification on the inside contacts of some zirconia agglomerates were observed in the early stages of sintering. The intermediate-mixed powders had slightly lower hardness values as a whole but higher fracture toughness compared to that of the initial-mixed powders.
\end{abstract}

Key words zirconia, alumina, toughness, agglomerate, ball-mill.

\section{1. 서 론}

세라믹스 재료는 일반적으로 강도나 경도 등의 기계적 인 물성이 다른 재료보다 매우 뛰어남에도 불구하고 강 한 취성파괴 현상 때문에 구조 혹은 엔지니어링 세라믹 스로서의 사용에 많은 제약을 받고 있다. 따라서 이러 한 세라믹스재료의 인성을 증가시키려는 시도는 최근 수 십년동안 구조재료 연구의 매우 중요한 부분을 차지하 여 왔다.

1975년 Garvie 등이 지르코니아의 응력 유기 상변태 에 의한 강인화 기구를 보고한 이래, 변태강화 지르코 니아(Transformation Toughened Zirconia, TTZ)가 새로
운 형태의 기계·구조용 세라믹스로서 주목받기 시작하 였다. ${ }^{1-3)}$

지르코니아의 상전이에 따른 강화효과를 이용하는 복 합재료 중 가장 대표적인 것이 알루미나 기지상에 지르 코니아 입자를 분산시킨 ZTA(Zirconia Toughened Alumina)와 지르코니아 기지상에 알루미나 입자를 분산시킨 ATZ(Alumina Toughened Zirconia)이다. ${ }^{4)}$

$\mathrm{ZTA}$ 의 경우에는 정방정계 지르코니아가 단사정계로 상 전이시 발생하는 체적팽창이 기지상인 알루미나에 의해 억제되기 때문에, 비교적 낮은 함량 $(<10 \mathrm{vol} \%)$ 의 지르코 니아가 포함된 ZTA에서는 안정화제 없이도 상온에서 정 방정계 지르코니아가 존재할 수 있다. ${ }^{5)}$ 또한 같은 이유

\footnotetext{
${ }^{\dagger}$ Corresponding author

E-Mail : jhsohn@kaya.ack.kr (J. Sohn, Kaya Univ.)
}

(C) Materials Research Society of Korea, All rights reserved.

This is an Open-Access article distributed under the terms of the Creative Commons Attribution Non-Commercial License (http://creativecommons.org/licenses/by-nc/3.0) which permits unrestricted non-commercial use, distribution, and reproduction in any medium, provided the original work is properly cited. 
로 해서 정방정계 입자의 임계크기도 TZP(Tetragonal Zirconia Polycrystals)의 2배 가량이 되기도 한다. ${ }^{6}$

Garvie는 지르코니아가 상온에서 안정화되는 이유를 입 자크기 효과 면에서 관찰하였으며 이때의 임계입자크기 는 $0.3 \mu \mathrm{m}$ 정도라고 보고하였다. $\left.{ }^{6}\right)$ 그러나, 알루미나 기 지에 분산된 상태의 지르코니아는 기지의 상변태 억제 효과로 인해 실제로 $0.6 \sim 1.0 \mu \mathrm{m}$ 까지 정방정상이 안정할 수 있고 기지의 elastic modulus가 증가할수록 임계 입 자크기는 증가하게 된다. ${ }^{5,7-9)}$

그러나 실질적으로 $\mathrm{ZTA}$ 의 주요 특성인 인성은 지르 코니아 입자크기가 감소할수록 증가하는 것으로 알려져 있다. ${ }^{10)}$ 본 연구에서는 비표면적이 $16 \mathrm{~m}^{2} / \mathrm{g}$ 이고 결정자 크 기(crystalline size)가 $220 \AA$ 인 3Y-TZP 지르코니아 분말 을 사용하여 볼밀 초기부터 지르코니아를 알루미나에 혼 합했을 경우와 지르코니아만을 장입하여 볼 밀링을 일 정시간 행한 후 알루미나를 혼합했을 경우에 대해서 혼 합방식의 차이가 최종적으로 $\mathrm{ZTA}$ 의 밀도, 미세구조, 경 도 및 파괴인성에 미치는 영향을 알아보고자 하였다. $\mathrm{Al}_{2} \mathrm{O}_{3}$ 원료 분체로는 일본 스미토모사의 상용 분말 $(99.8 \%)$ 을 사용하였으며 $\mathrm{ZrO}_{2}$ 의 첨가량은 $15 \mathrm{wt} \%$ 로 고정하였다.

\section{2. 실험 방법}

본 연구에서는 출발원료로 $\alpha-\mathrm{Al}_{2} \mathrm{O}_{3}$ (AES-11, SUMITOMO Co., Japan)와 비표면적이 $16 \mathrm{~m}^{2} / \mathrm{g}$ 인 3Y-TZP(3YEM, AMS Co., Korea)를 사용하였다. 실험에서 사용한 AES-11은 $\alpha-\mathrm{Al}_{2} \mathrm{O}_{3}$ 로서 예비실험에서 측정한 평균입경은 $0.45 \mu \mathrm{m}$ 로 나타났다. 이 $\alpha-\mathrm{Al}_{2} \mathrm{O}_{3}$ 에 3 Y-TZP 분말의 첨가량은 15 $\mathrm{wt} \%$ 로 정하였고 직경 $5 \mathrm{~mm}$ 와 $10 \mathrm{~mm}$ 지르코니아볼이 무게비 $1: 1$ 로 내장된 $1 l$ 용량의 $\mathrm{PE}$ 용기에 장입하여 볼 밀을 행하였다. 이때 분산매로는 물을 사용하였으며 분 산제로는 Cerasperse $5468 \mathrm{CF}$ (Sannopco, Japan), 결합제 로는 PVA \#500(10 wt\% 수용액), 가소제로는 에틸렌글리 콜(덕산, 한국), 소포제는 SN-defoamer 485(Sannopco, Japan)를 사용하였다. 원료분체:물 그리고 슬러리:볼의 부 피비는 각각 $1: 1.2$ 와 $1: 1$ 이었다. 그리고 각각의 첨가제는 원료분체에 대해 분산제 $0.8 \mathrm{wt} \%$, 결합제 $1 \mathrm{wt} \%$, 가소 제 $0.1 \mathrm{wt} \%$, 소포제 $0.04 \mathrm{wt} \%$ 로 고정하여 첨가하였다.

$\alpha-\mathrm{Al}_{2} \mathrm{O}_{3}$ 에 $3 \mathrm{Y}-\mathrm{TZP}$ 를 혼합할 때 두 가지의 혼합방법 을 사용하였다. 첫 번째 방법으로는 $3 \mathrm{Y}-\mathrm{TZP}$ 분말만 장 입하여 20 시간을 볼밀한 후 $\alpha-\mathrm{Al}_{2} \mathrm{O}_{3}$ 를 첨가하고 다시 20 시간을 볼밀하여 전체 볼밀시간을 40 시간으로 맞추었으 며 이 분말을 중간혼합분말(Intermediate-mixed powders) 로 칭하였다. 두 번째 방법으로는 처음부터 $\alpha-\mathrm{Al}_{2} \mathrm{O}_{3}$ 와 $3 \mathrm{Y}-\mathrm{TZP}$ 를 함께 혼합하여 40 시간을 볼밀하였으며 이 분 말은 초기혼합분말(Initial-mixed powders)로 칭하였다.
40시간 볼밀 후 얻어진 각각의 슬러리는 주입성형법에 의해 성형체로 만들어졌다. $5 \mathrm{~mm}$ 이상의 시편 두께를 얻 기 위하여 2시간 이상 캐스팅 하였으며 얻어진 성형체 는 3 일 동안 건조시킨 후 사용하였다. 성형체의 소결은 칸탈 발열체를 사용한 전기로에서 행하였으며 $10^{\circ} \mathrm{C} / \mathrm{min}$ 로 $1000{ }^{\circ} \mathrm{C}$ 까지, $5^{\circ} \mathrm{C} / \mathrm{min}$ 로 $1300{ }^{\circ} \mathrm{C}$ 까지, 이후에는 1.6 ${ }^{\circ} \mathrm{C} / \mathrm{min}$ 의 승온속도로 소결온도에 도달하여 2 시간동안 유 지한 후 로냉하였다.

볼밀된 분체의 입도분석은 레이져 회절 입도분석기 (LA950V2, HORIBA, Japan)를 사용하였다. 성형체의 밀 도는 칫수법으로 계산하였으며, 소결체의 밀도는 액중칭 량법(Archimedes법)으로 측정하였다. 결정상 분석은 X-선 회절분석장치(XRD: M03X-HF, MacScience Co., Ltd., Japan)를 사용하여 분석하였으며 측정조건은 Target 전력 $30 \mathrm{kV}-30 \mathrm{~mA}, \mathrm{Cu}$ target, CS method(Sampling width: $0.04 \mathrm{deg}$, Scan Speed: $4.00 \mathrm{deg} / \mathrm{min}$ ), 그리고 $20 \leqq 2 \theta \leqq$ $60^{\circ}$ 로 하였다. 소결시편의 미세구조는 주사전자현미경 (Scanning Electron Microscope(JEOL, JSM-6701F))으로 관찰하였으며 경도와 파괴인성은 Vickers Hardness Tes$\operatorname{ter}(452 \mathrm{SVD}$, Wilson-Wolpert, USA)를 사용하여 측정하 였다.

\section{3. 결과 및 고찰}

Fig. 1은 혼합조건이 다른 두 분말을 사용하여, 주입 성형법으로 성형체를 만든 후 측정한 XRD 패턴을 나 타낸 것이다. 지르코니아의 첨가량을 $15 \mathrm{wt} \%$ 로 고정하였 으므로 두 혼합분말간에 패턴상의 큰 차이점은 나타나 지 않고 있으나, 중간혼합분말에 있어서 지르코니아의 회 절강도가 약간 낮아지고 회절피크의 반가폭 확장(peak broadening) 현상이 나타나고 있음을 알 수 있다. 회절

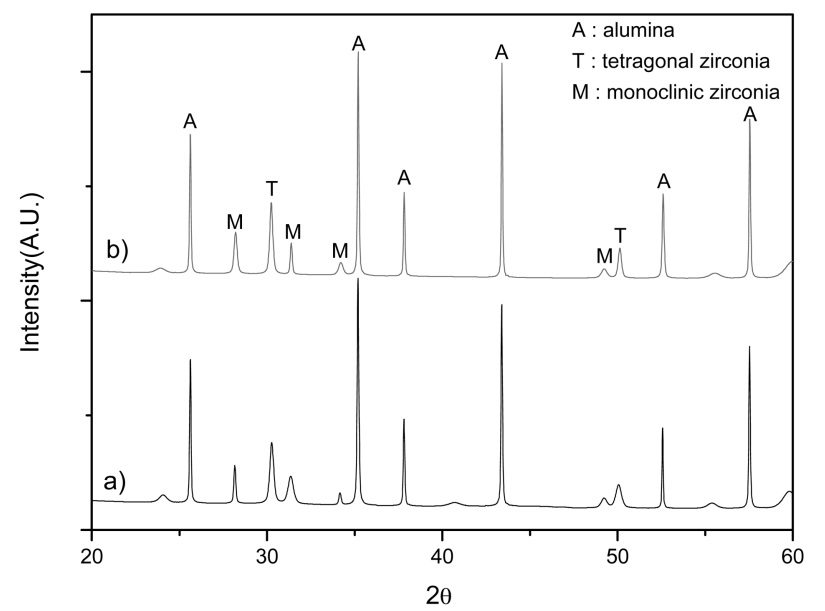

Fig. 1. XRD patterns of green body prepared from a) intermediatemixed powders and b) initial-mixed powders. 


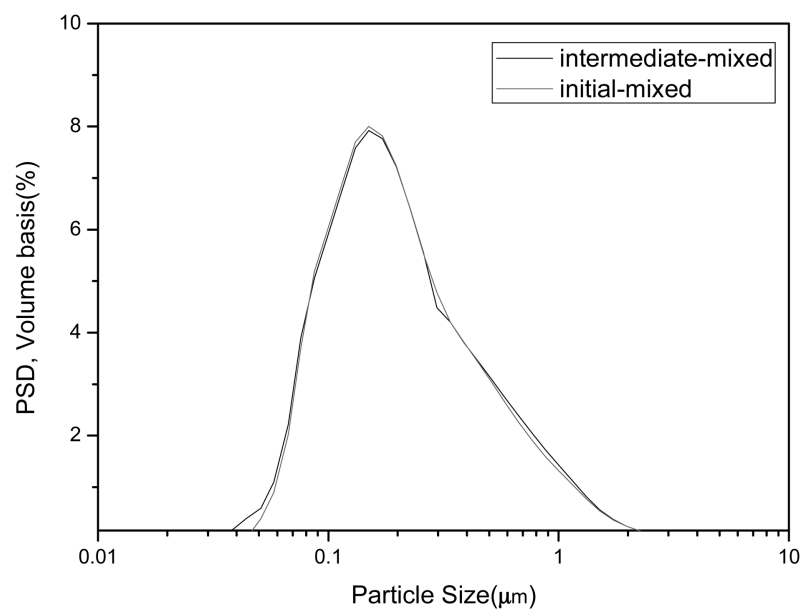

Fig. 2. Particle size distribution of intermediate-mixed powders and initial-mixed powders.

피크의 반가폭 확장 현상은 분말의 입자크기가 $0.1 \mu \mathrm{m}$ 이하로 감소할 때 나타나는 현상으로서 중간혼합분말의 경우 초기에 지르코니아만 장입하여 20시간 볼밀을 행 하였으므로 볼밀에 의한 지르코니아의 분쇄효과가 더 잘 나타난 결과로 생각된다. 또한 안정화제가 첨가된 $3 \mathrm{Y}-$ TZP 분말을 사용하였음에도 불구하고 단사정(monoclinic) 에 의한 회절피크가 관찰되는 것은 안정화제의 첨가효 과가 소결 후 냉각과정에서 나타나는 것으로 안정화제 가 첨가되기는 하였으나 아직 소결과정을 거치지 않았 기 때문인 것으로 생각된다.

Fig. 2에는 두 종류의 분말에 대한 입도분석결과를 나 타내었다. 두 분말 모두 평균입경이 $0.27 \mu \mathrm{m}$ 을 나타내어 차이가 없었으나 입도분포에 있어서는 약간의 차이가 나 타나고 있다. 중간혼합분말의 경우 초기혼합분말에 비해 $0.5 \mu \mathrm{m}$ 보다 큰 입자의 부피분율이 미세하게 증가하였으며 $0.07 \mu \mathrm{m}$ 보다 작은 입자의 부피분율 역시 증가하였다. 볼 밀 전 측정한 알루미나의 입자크기가 $0.45 \mu \mathrm{m}$ 이었고 지 르코니아의 비표면적 $16 \mathrm{~m}^{2} / \mathrm{g}$ 을 이용하여 계산한 구형환 산평균입경이 $0.063 \mu \mathrm{m}$ 이므로, 중간혼합분말에서 큰 입 자의 부피분율이 증가한 것은 알루미나의 볼밀시간 감 소에 의한 것으로 볼 수 있고 작은 입자의 부피분율이 증가한 것은 미세한 입자크기로 인해 응집체를 형성하 고 있던 지르코니아 입자가 볼밀의 효율성 증가에 의해 더 많이 분산된 것으로 생각된다.

Fig. 3은 두 종류의 혼합분말로 제조한 성형체를 1400 , 1450,1500 그리고 $1550{ }^{\circ} \mathrm{C}$ 에서 2 시간 동안 소결한 후 로냉한 시편의 소결밀도를 나타낸 것이다. 두 종류의 성 형체 모두 $1400^{\circ} \mathrm{C}$ 를 지나면서 빠르게 치밀화가 진행되 어 $1500{ }^{\circ} \mathrm{C}$ 에서 포화밀도에 도달함을 알 수 있다. 그러 나 소결밀도에 있어서는 중간혼합분말의 경우 초기혼합 분말에 비해 다소 낮은 상대밀도를 보여주고 있음을 알

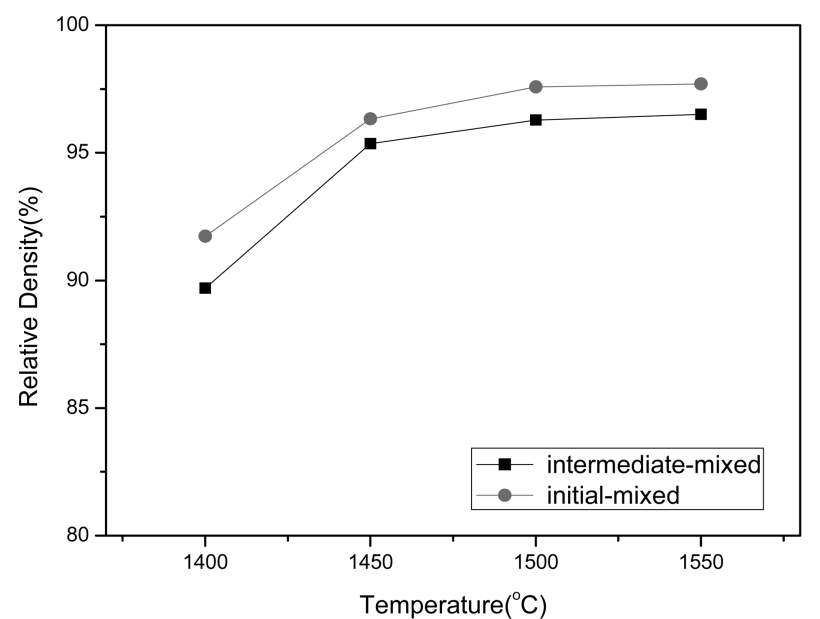

Fig. 3. Changes in relative density of ZTA composites prepared from intermediate-mixed powders and initial-mixed powders with sintering temperature.

수 있다. 이는 중간혼합분말의 경우 $\mathrm{XRD}$ 패턴과 입도분 석결과에서 알 수 있듯이 응집체를 이루고 있던 지르코 니아 입자의 분산성이 초기혼합분말에 비해 더 좋아졌 기 때문인 것으로 생각된다. 즉, 중간혼합분말의 경우 볼 밀 초기에 지르코니아만 장입하여서 볼운동에 의한 응 집체 파괴효과가 충분히 나타난 후 알루미나를 첨가함 으로서, 처음부터 알루미나와 지르코니아를 함께 장입했 던 초기혼합분말에 비해 파괴된 응집체의 수가 더 많아 지게 되고 이로 인해 분산된 지르코니아 입자의 개수 역 시 더 많아지게 되어서 제 2 상 첨가에 의한 치밀화 억 제효과가 더 잘 나타난 경우라고 볼 수 있다.

Fig. 4는 중간혼합분말을 이용하여 제조한 시편의 소 결온도에 따른 미세구조 변화를 보여주는 SEM 사진을 나타낸 것이다. 사진에서 검은 부위는 모상인 알루미나 이고 흰 부위는 제 2 상인 지르코니아이다. 전체적으로 알 루미나 기지내에 지르코니아가 잘 분산되어 있음을 알 수 있다. 지르코니아는 입계 혹은 triple junction에 포획 되어 drag force로서 입계이동속도를 감소시키지만 소결 온도가 상승하게 되면 지르코니아의 입자성장기구인 합 체에 의해 입자성장을 하게 된다. 합체에 의한 입자성장 은 제 2 상이 입계와 함께 움직일 수 있을 만큼의 충분한 자기확산계수를 가질 때 일어난다고 알려져 있다. 이 후 소결온도가 더욱 상승하게 되면 Fig. 4 d)에서처럼 합체 에 의한 지르코니아의 입자성장이 더욱 촉진되고, 빨라 진 입계이동속도를 따라가지 못하는 경우에는 알루미나 기지내에 포획되기도 한다.

Fig. 5에는 초기혼합분말을 이용하여 제조한 시편의 소 결온도에 따른 미세구조 변화를 보여주는 SEM 사진이 다. 전체적으로 중간혼합분말에 비해 미세구조내에 일부 크게 성장한 지르코니아 입자가 분포하고 있음을 알 수 

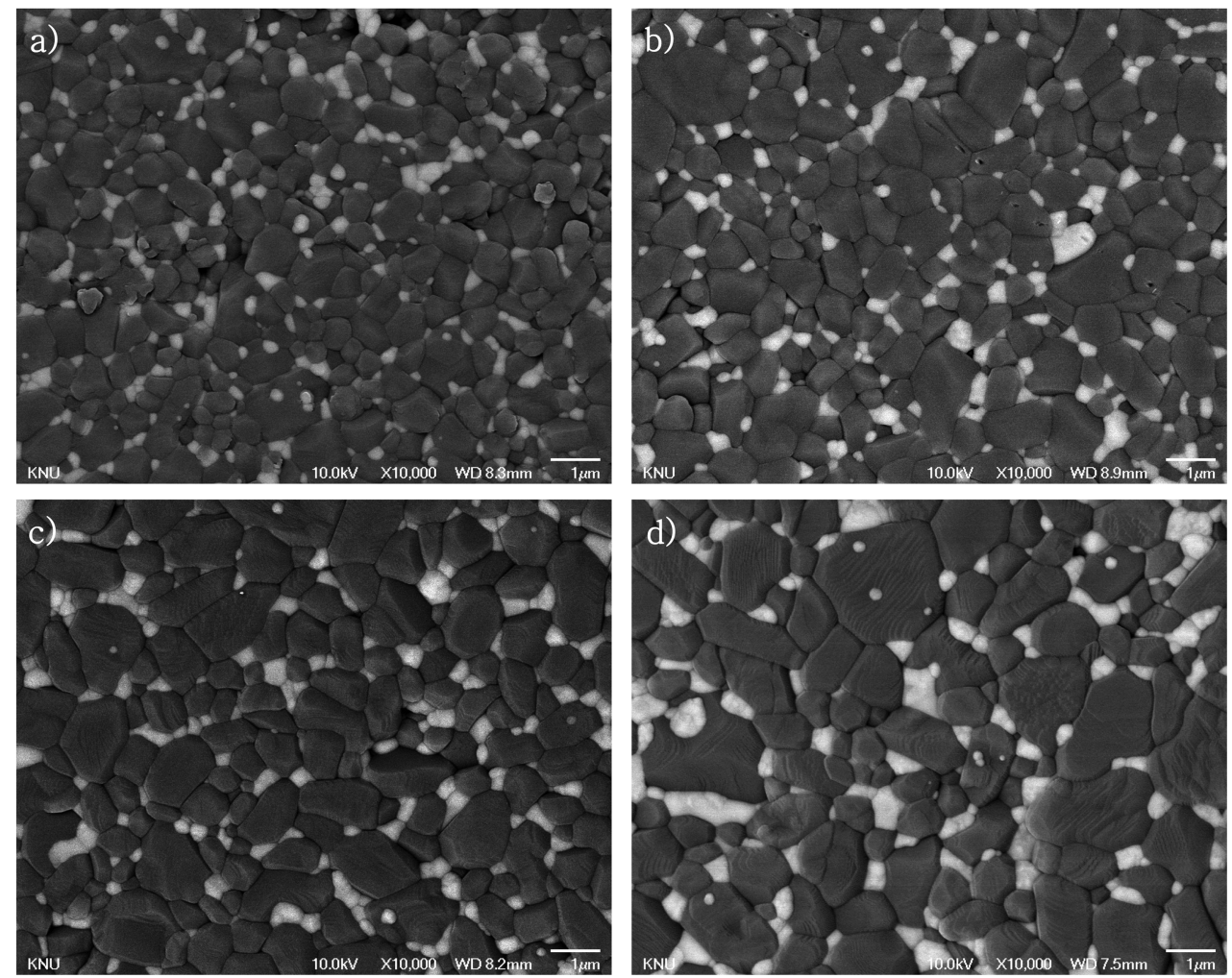

Fig. 4. SEM photographs of ZTA composites(intermediate-mixed powders) sintered at a) $1400{ }^{\circ} \mathrm{C}$, b) $1450{ }^{\circ} \mathrm{C}$, c) $1500{ }^{\circ} \mathrm{C}$ and d) $1550{ }^{\circ} \mathrm{C}$ for 2 hours.
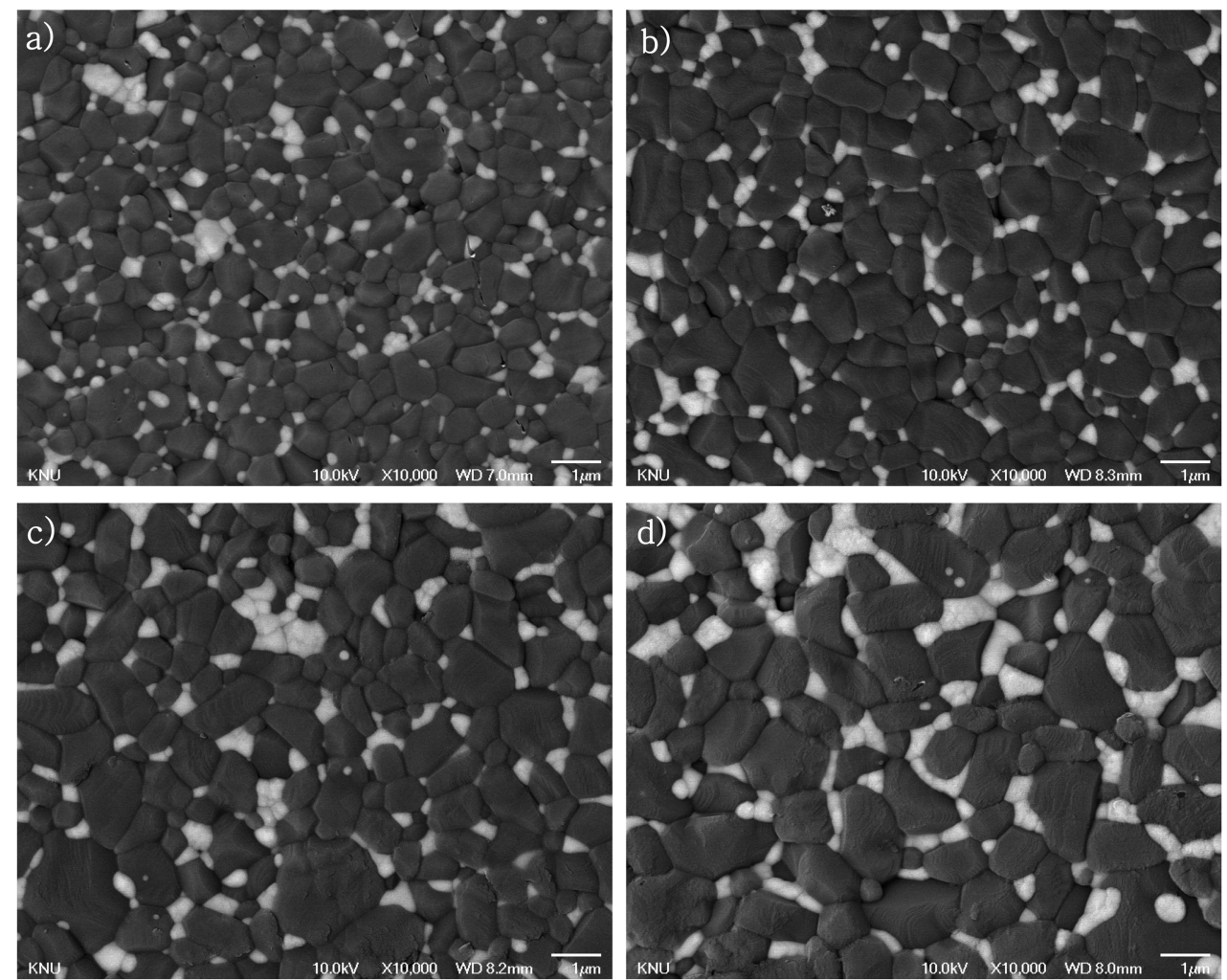

Fig. 5. SEM photographs of ZTA composites(initial-mixed powders) sintered at a) $1400{ }^{\circ} \mathrm{C}$, b) $1450{ }^{\circ} \mathrm{C}$, c) $1500{ }^{\circ} \mathrm{C}$ and d) $1550{ }^{\circ} \mathrm{C}$ for 2hours. 


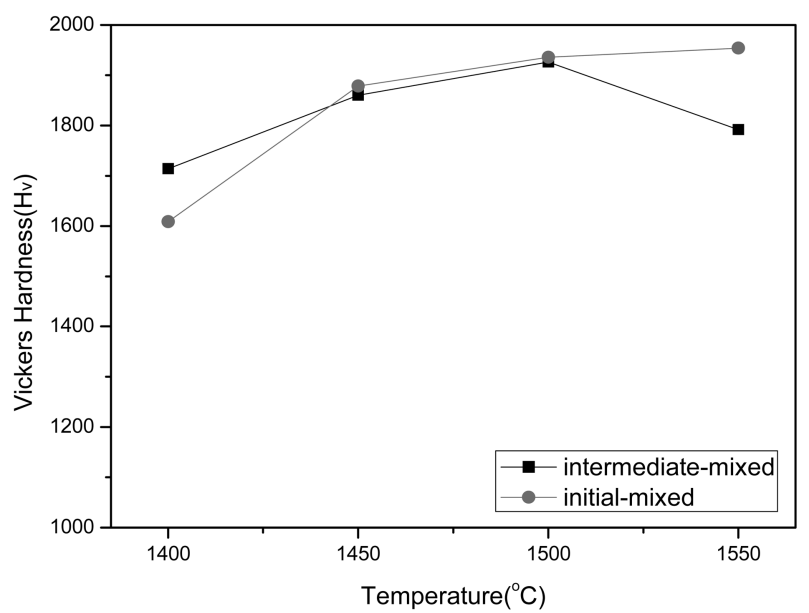

Fig. 6. Changes in Vickers Hardness of ZTA composites prepared from intermediate-mixed powders and initial-mixed powders with sintering temperature.

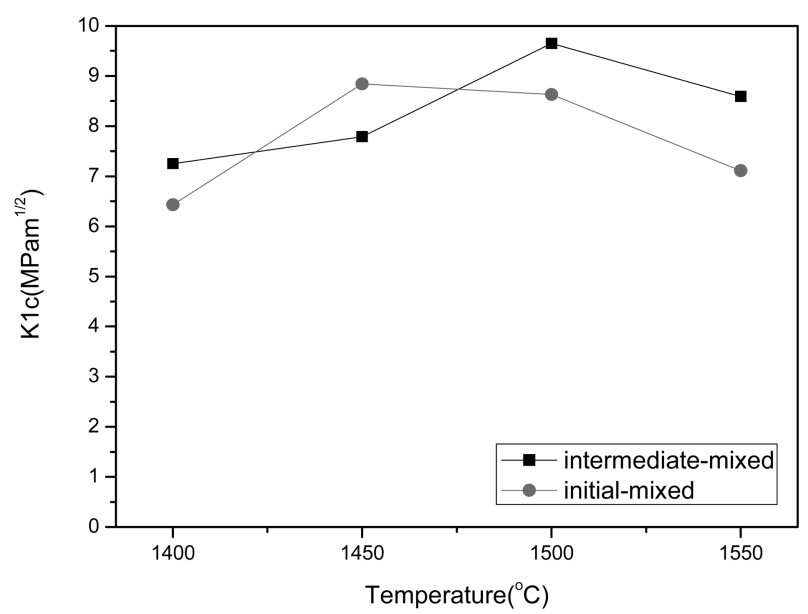

Fig. 7. Changes in Fracture Toughness $\left(\mathrm{K}_{1 \mathrm{c}}\right)$ of ZTA composites prepared from intermediate-mixed powders and initial-mixed powders with sintering temperature.

있다. 이러한 결과는 $1400{ }^{\circ} \mathrm{C}$ 에서 소결한 시편에서도 관 찰되고 있으며 이는 볼밀과정에서 일부 미분쇄된 지르 코니아 응집체 내부의 입자 접촉부에서 일어나는 부분 적인 조기 치밀화에 따른 것으로 추정된다. 온도가 증 가함에 따라 지르코니아의 합체에 의한 입자성장도 더 해져서 $1550^{\circ} \mathrm{C}$ 에서는 크게 성장한 지르코니아 입자들이 관찰되고 있다.

Fig. 6에는 두 종류의 혼합 분말로 제조한 소결체에 대 해서 Vickers Hardness Tester(452SVD, Wilson-Wolpert, $\mathrm{USA}$ )를 사용하여 $2 \mathrm{kgf}$ 의 하중으로 10 초간 유지한 후 측 정한 Vickers Hardness 값을 나타내었다. 초기혼합분말은 연속적으로 상승하는 경향을 보여주고 있으며 $1550{ }^{\circ} \mathrm{C}$ 에 서는 1953.57 의 최고값을 나타내었다. 중간혼합분말 역 시 연속적으로 상승하는 경향을 보여주고 있으나 $1500{ }^{\circ} \mathrm{C}$
에서 최고값인 1926.23 을 기록한 후 다시 감소하게 된 다. 전체적으로는 중간혼합분말이 초기혼합분말보다 더 낮 은 경도값을 가지고 있다.

Fig. 7에는 두 종류의 혼합 분말로 제조한 소결체에 대 해서 Vickers Hardness Tester(452SVD, Wilson-Wolpert, USA)를 사용하여 $10 \mathrm{kgf}$ 의 하중으로 10 초간 유지한 후 측정한 파괴인성 $\left(\mathrm{K}_{1 \mathrm{c}}\right)$ 값을 나타내었다. 전체적으로는 두 종류의 혼합분말 모두 상승 후 다시 감소하는 추세를 보 여주고 있다. 중간혼합분말의 경우, 상승 이후 $1500{ }^{\circ} \mathrm{C}$ 에서 최고값인 $9.65 \mathrm{MPa} \sqrt{\mathrm{m}}$ 을 기록한 후 감소하였고 초 기혼합분말의 경우 $1450{ }^{\circ} \mathrm{C}$ 에서 최고값인 $8.84 \mathrm{MPa} \sqrt{\mathrm{m}}$ 에 도달한 후 감소하였다. 초기혼합분말의 경우 볼밀과정에 서 미분쇄된 지르코니아 응집체로 인해 지르코니아 입 자의 부분적인 조기 치밀화가 진행되어 소결초기 단계 에서부터 크게 성장한 지르코니아 입자들이 존재하게 되 고 이로 인해 파괴인성의 최고값 도달온도가 낮아진 것 으로 추정된다.

\section{4. 결 론}

본 연구에서는 지르코니아를 알루미나에 혼합하는데 있 어 볼밀의 초기에는 지르코니아만 장입하고 볼밀중간에 알루미나를 혼합하는 중간혼합분말과 볼밀의 초기에 지 르코니아와 알루미나를 함께 장입하는 초기혼합분말을 제 조하여 이러한 혼합방법의 차이가 기계적 특성에 미치 는 영향을 알아보았다.

1) 중간혼합분말에서 알루미나의 볼밀시간 감소에 의 해 큰 입자의 부피분율이 미세하게 증가하였으나, 지르 코니아만 장입하고 행한 초기볼밀로 인해 응집체를 형 성하고 있던 지르코니아 입자들이 초기혼합분말에 비해 더 많이 분산되었다.

2) 중간혼합분말의 경우, 초기혼합분말에 비해 파괴된 지르코니아 응집체의 수가 더 많으므로 분산된 지르코 니아 입자의 개수 역시 더 많아지게 되어서 제2상 첨 가에 의한 치밀화 억제효과가 더 잘 나타난다.

3) 중간혼합분말의 경우 균일하게 지르코니아가 분산 된 미세구조를 가지며 소결온도가 상승함에 따라 지르 코니아 입자간의 합체에 의한 입자성장을 하게 되나 초 기혼합분말의 경우에는 일부 미분쇄된 지르코니아 응집 체 내부의 입자 접촉부에서 일어나는 부분적인 조기 치 밀화에 의해 소결초기 단계에서도 크게 성장한 지르코 니아 입자가 관찰되고 있다.

4) 중간혼합분말은 초기혼합분말에 비해 전체적으로 다 소 낮은 경도값을 가지나 파괴인성에 있어서는 더 높은 최고값 $(9.65 \mathrm{MPa} \sqrt{\mathrm{m}})$ 을 나타내었다. 


\section{References}

1. R. C. Garvie, R. H. Hannik and R. T. Pascoe, Nature, 258, 703 (1975).

2. D. B. Marshall, J. Am. Ceram. Soc., 69(3), 173 (1986).

3. R. H. J. Hannink, P. M. Kelly and B. C. Muddle, J. Am. Ceram. Soc., 83(3), 461 (2000).

4. M. Szutkowska, J. Achiev. Mater. Manuf. Eng., 54(2), 202 (2012).

5. F. F. Lange, J. Mater. Sci., 4(17), 247 (1982).
6. R. C. Garvie, Adv. Ceram., 12, 55 (1984).

7. G. Orange, G. Fantozzi, P. Homerin, F. Thevenot, A. Leriche and F. Cambier, Adv. Ceram., 24, 1075 (1988).

8. A. H. De Aza, J. Chevalier, G. Fantozzi, M. Schehl and R. Torrecillas, Biomaterials, 23, 937 (2002).

9. C. W. Huang, M. T. Weng and W. C. J. Wei, J. Ceram. Process. Res., 9(3), 221 (2008).

10. A. Alsebaie, A. G. Olabi, A. Rafferty and T. Prescott, The fourth Arabic congress in material science, 2, 390, Al. fath university, Libya, (2005). 